
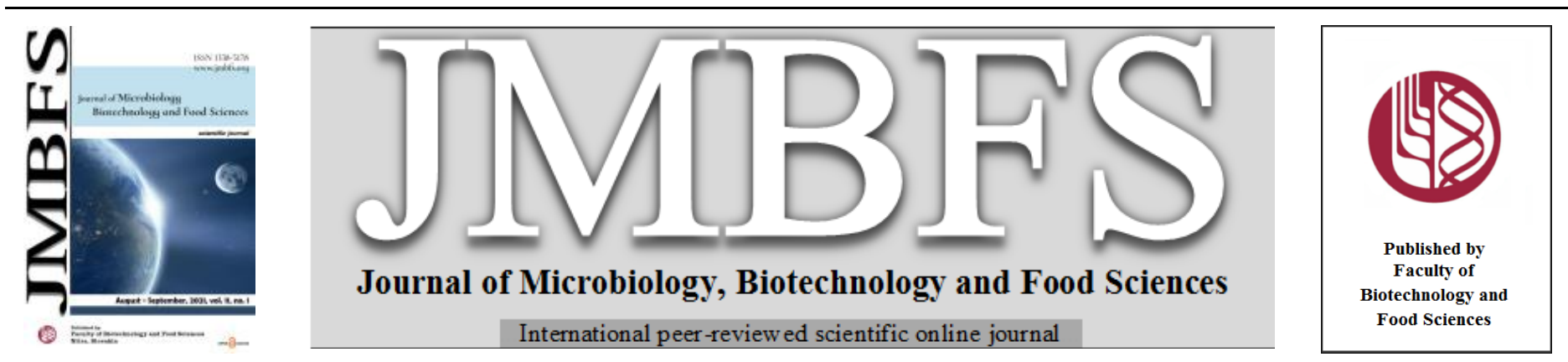

\title{
A NEW ROLE OF METFORMIN AS AN EFFLUX PUMP INHIBITOR IN KLEBSIELLA PNEUMONIA
}

\author{
Hisham Abbas * ${ }^{l}$, Ghada Shaker ${ }^{1}$, Randa Khattab ${ }^{2}$, Momen Askoura ${ }^{1}$ \\ Address(es): Dr. Hisham Abbas, PhD., \\ ${ }^{1}$ Zagazig University, Faculty of Pharmacy, Department of Microbiology and Immunology, 44519, Zagazig, Egypt. \\ ${ }^{2}$ Ministry of health, Police authority hospital, Egypt.
}

*Corresponding author: hishamabbas2008@gmail.com

https://doi.org/10.15414/jmbfs.4232

\section{ARTICLE INFO}

Received 19. 1. 2021

Revised 24. 2. 2021

Accepted 3. 3. 2021

Published 1. 8. 2021

Regular article

open $O$ access

\begin{abstract}
Respiratory tract infections caused by Klebsiella pneumoniae are frequently associated with high mortality and morbidity rates. Treatment of these infections is usually difficult due to the emergence of multiple resistances to antibiotics. Multidrug efflux pumps are greatly involved in antibiotic resistance in Gram-negative bacteria including Klebsiella pneumoniae. In the current study, efflux activity was observed in $93.75 \%$ of Klebsiella pneumoniae clinical isolates by the qualitative acridine orange agar method. This finding was further confirmed genotypically by polymerase chain reaction that showed the presence of efflux genes AcrA, AcrB, TolC and $m d t k$ in these isolates. The ability of metformin to inhibit efflux activity was compared with the reference efflux pump inhibitors verapamil and ascorbic acid. Metformin was more active than ascorbic acid and less active than verapamil. Up to our knowledge, this is the first report that shows that metformin has an efflux pump-inhibiting activity in Klebsiella pneumoniae.
\end{abstract}

\section{INTRODUCTION}

Respiratory tract infection (RTI) is one of the most common infections which causes morbidity and mortality if untreated (Prajapati et al., 2011). Klebsiella pneumoniae is considered one of the most common bacteria that cause RTI and it is the classical cause of Gram-negative bacillary pneumonia (Kombade and Agrawal, 2014). Once established, pneumonia caused by $K$. pneumoniae is extremely difficult to control and the mortality rates, even for treated patients, may be higher than $50 \%$ (Saini et al., 2009). K. pneumoniae is a facultative anaerobic encapsulated Gram-negative bacillus that belongs to the family Enterobacteriaceae (Iyer $\boldsymbol{e t}$ al., 2019). It is a common opportunistic hospitalassociated pathogen that is responsible for about one third of all Gram-negative infections, and is the $8^{\text {th }}$ most common nosocomial pathogen (Surgers et al., 2019). In addition to pneumonia, $K$. pneumoniae can cause urinary tract infections, cystitis, surgical wound infections and fatal infections, such as septicemia and endocarditis (Upadhyay and Parajuli, 2013).

The hallmark of $K$. pneumoniae infection is the difficult therapy due to its high multiple intrinsic antibiotic resistance, that leads to the low efficacy of antibiotic therapy. Nosocomial K. pneumoniae was found to have a high rate of resistance against commonly used antibiotics such as penicillins, fluoroquinolones, aminoglycosides, macrolides in addition to tetracyclines, folate inhibitors, lincosamides and phenicols (Shi $\boldsymbol{e t}$ al., 2013, Sun $\boldsymbol{e t}$ al., 2014). Mechanisms of resistance production of hydrolytic or modifying enzymes, mutations in antibiotics' transporters impeding their entrance and use of energy-dependent efflux pumps to extrude the antibiotics, impairing their accessibility to the target (Chikere et al., 2008). Bacteria are termed multidrug resistant (MDR) when they display resistance to three or more classes of antibiotics. Not only MDR isolates of $K$. pneumoniae are common, but also extensively drug-resistant and pan-drugresistant strains of $K$. pneumoniae have been found (Singh et al., 2017).

One of the most important reasons for MDR in $K$. pneumonia is the presence of active efflux pumps that export several structurally unrelated antimicrobial agents outside bacterial cells (Filgona $\boldsymbol{e t}$ al., 2015). Bacterial efflux pumps or transporters are categorized on the basis of bioenergetical and structural features into two major families; ATP-binding cassette $(\mathrm{ABC})$ primary transporters or single drug transporters that hydrolyze ATP to be used as a source of energy and secondary or MDR transporters that use the proton (or sodium) gradient as an energy source (Fournier et al., 2006). Secondary transporters include four families; multidrug and toxic compound extrusion (MATE), major facilitator (MF), resistance-nodulation-division (RND) and small multidrug resistance (SMR) (Auda et al., 2020). Resistance Nodulation Division (RND) efflux pumps represent a major type of efflux pumps in Gram-negative bacteria. they are responsible for the resistance to many biocides, heavy metals, and antibiotics such as penicillins, cephalosporins, aminoglycosides, tetracyclines, macrolides and fluoroquinolones ( Li et al., 2015).

K. pneumoniae have AcrAB and MdtK efflux pump systems that are members of the RND and MATE family efflux pumps; respectively. The AcrAB-TolC pump is a tripartite pump that is composed of a periplasmic component (AcrA), a secondary transporter located in the inner membrane (AcrB) and outermembrane channel (TolC) (He et al., 2015). This pump is involved in MDR to different classes of antibiotics such as quinolones and tetracyclines (Du et al., 2014). Efflux pumps of the type MdtK can expel some antimicrobial agents (Sun et al., 2014). On the other hand, OmpK 35 and OmpK36 porins are essential ports for the entry of cephalosporins and carbapenems into bacterial cells (Shi $\boldsymbol{e t}$ al., 2013). These facts signify the detection of such antibiotic resistance genes in K. pneumoniae strains isolated from health care associated infections (Ranjbar et al., 2019).

Due to the role of efflux pumps in antibiotic resistance, it is of great importance to find out drugs that can inhibit efflux pumps, so that they can be used to reverse antibiotic resistance (Kabra et al., 2019). Verapamil is a calcium channel blocker that was identified to block bacterial efflux pumps in vitro (Li and Nikaido, 2009). Verapamil was found to enhance bacterial killing in mice infected with drug-resistant and -sensitive bacteria in murine tuberculosis models (Louw et al., 2011) in addition to its ability to reduce relapse rates (Gupta et al., 2017). Moreover, ascorbic acid exerted efflux pump-inhibiting activity in E. coli, by which it augmented the antimicrobial activity against E. coli (Serry et al., 2008).

Metformin (1, 1-dimethylbiguanide hydrochloride) is a common hypoglycemic biguanide drug used for the treatment of type 2 diabetes mellitus (Martins et al., 2013). Metformin was reported to inhibit breast cancer cell growth (Zakikhani $\boldsymbol{e t}$ al., 2006) and to combat breast cancer chemo-resistance (Vazquez-Martin et al., 2009). There is a significant substrate overlap observed between bacterial and mammalian efflux pumps P-glycoproteins (P-gp). Due to this overlap, many mammalian MDR inhibitors, such as reserpine, verapamil and piperine can inhibit bacterial efflux pumps (Neyfakh et al., 1991). Metformin significantly inhibited MDR1 gene expression that encodes P-gp in cancer cells by blocking MDR1 gene transcription. Moreover, metformin significantly increased the intracellular accumulation of the fluorescent P-gp substrate rhodamine-123 (Kim et al., 2011). This study aimed to investigate efflux pumps as a mechanism of antibiotic resistance in $K$. pneumoniae phenotypically and genotypically and to assess metformin as a potential efflux pump inhibitor. 


\section{MATERIALS AND METHODS}

\section{Media and chemicals}

Müeller-Hinton agar (MHA), Müeller-Hinton broth (MHB) and nutrient agar were obtained in dehydrated form from OXOID, Hampshire, England. Tryptone soya broth (TSB) was obtained in dehydrated form from LAB M, LIMITED, Lancashire, United Kingdom. Meropenem was obtained from ASTRA ZENECA UK Limited, Inc, United Kingdom. Amoxicillin, ethidium bromide and acridine orange were obtained from SIGMA, St. Louis, Mo, USA. Cefoperazone-sulbactam and ampicillin-sulbactam were obtained from EGYPTIAN PHARMACEUTICAL INDUSTRIES COMPANY (EPICO), Tenth of Ramadan City, Egypt. Azithromycin was obtained from PFIZER Company. Ciprofloxacin was obtained from AMRYIA PHARMCEUTICAL INDUSTRY CO., Alexandria, Egypt, amikacin from GLAXOSMITHKLINE, Brentford, London, and cefepime and tetracycline from PHARCOB INTERNATIONAL, Alexandria, Egypt. PCR master mix, My Taq ${ }^{\text {TM }}$ Red Mix (2X), agarose DNA grade, DNA marker (100 bp), Tris-acetate-EDTA (TAE) buffer (50X) and the PCR primers (Table 1), provided by Integrated DNA Technologies, were obtained from SIGMA, St. Louis, Mo, USA. DNase free water used for PCR reaction mixture was obtained from THERMO FISHER SCIENTIFIC, Waltham. MA, USA

\section{Bacterial strains}

Seventeen MDR Klebsiella pneumoniae clinical isolates were obtained from the culture collection of the Microbiology and Immunology department, Faculty of Pharmacy, Zagazig University. These isolates were recovered from sputum and tracheal swabs samples and were previously obtained from patients with nosocomial pneumoniae that were admitted to Zagazig and Tanta University Hospitals, Egypt.

Phenotypic screening of efflux pumps activity in multi-drug resistant bacteria by the acridine orange agar method

The potential efflux ability of the selected multi-drug resistant isolates was screened by assessment of their ability to efflux acridine orange (AO; N, N, N', N'tetramethylacridine-3, 6-diamine) by the acridine orange agar method. Bacterial isolates were inoculated in MHB until reaching mid-log phase of growth that matches $\mathrm{OD}_{600}$ of 0.6 . In each culture, a sterile swab was dipped and excess fluid was removed from each swab by touching the inner sides of the culture tube. MHA plates with increasing concentrations of $\mathrm{AO}$ ranging from 0.0 to $20 \mathrm{mg} / \mathrm{L}$ were prepared and swabbed from the center of the plate to its (Martins et al., 2011). The plates were incubated for $16 \mathrm{~h}$ at $37{ }^{\circ} \mathrm{C}$ and the fluorescence produced by the overlying bacterial streak was detected with a source of UV trans-illuminator. The plates were photographed and the lowest concentration of AO that showed fluorescence of the bacterial streak was recorded (Martins et al., 2013).

\section{Genotypic screening of efflux pump genes by PCR}

Seventeen MDR isolates were tested for the presence of three genes encoding for the multidrug efflux pump systems ( $a \mathrm{cr} A B$, tolC and $m d t k$ ) and two porin encoding genes (ompk35 and ompk36) encoding efflux pumps in K. pneumonia by PCR amplification technique. Specific primers used for amplification of $a c r A B$, tolC, $m d t k$, ompk35 and ompk36 genes are listed in Table 1.

Table 1 Primers used in PCR amplifications [27]

\begin{tabular}{|c|c|c|c|c|}
\hline Gene & Primer & 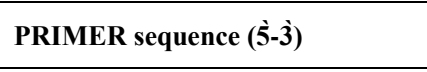 & $\begin{array}{l}\text { Annealing } \\
\text { temperature }\end{array}$ & Product size (bp) \\
\hline acrAB & $\begin{array}{l}\text { acrAB-F } \\
\text { acrAB-R }\end{array}$ & $\begin{array}{l}\text { ATCAGCGGCCGGATTGGTAAA } \\
\text { CGGGTTCGGGAAAATAGCGCG }\end{array}$ & $52^{\circ} \mathrm{C}$ & 312 \\
\hline tolC & $\begin{array}{l}\text { tolC-F } \\
\text { tolC- } \mathrm{R}\end{array}$ & $\begin{array}{l}\text { ATCAGCAACCCCGATCTGCGT } \\
\text { CCGGTGACTTGACGCAGTCCT }\end{array}$ & $52^{\circ} \mathrm{C}$ & 527 \\
\hline$m d t k$ & $\begin{array}{l}m d t k-\mathrm{F} \\
m d t k-\mathrm{R}\end{array}$ & $\begin{array}{l}\text { GCGCTTAACTTCAGCTCA } \\
\text { GATGATAAATCCACACCAGAA }\end{array}$ & $43^{\circ} \mathrm{C}$ & 453 \\
\hline ompk35 & $\begin{array}{l}\text { ompk35-F } \\
\text { ompk35-R }\end{array}$ & $\begin{array}{l}\text { CTCCAGCTCTAACCGTAGCG } \\
\text { GGTCTGTACGTAGCCGATGG }\end{array}$ & $52^{\circ} \mathrm{C}$ & 241 \\
\hline ompk36 & $\begin{array}{l}\text { ompk36-F } \\
\text { ompk36-R }\end{array}$ & $\begin{array}{l}\text { GAAATTTATAACAAAGACGGC } \\
\text { GACGTTACGTCGTATACTACG }\end{array}$ & $43{ }^{\circ} \mathrm{C}$ & 305 \\
\hline
\end{tabular}

Legend: bp: base pair, F: forward primer, R: reverse primer

The crude cell lysate was prepared according to Nair and Venkitanarayanan (2006). Overnight cultures of each isolate on nutrient agar were prepared. Two or three colonies were suspended in $50 \mu \mathrm{L}$ PCR- quality water that was heated at $95^{\circ} \mathrm{C}$ for 10 minutes in PCR thermocycler. The suspension was quickly centrifuged at $13000 \mathrm{rpm}$ for 30 seconds to separate DNA-containing supernatant that was stored at $-20^{\circ} \mathrm{C}$ for use in the PCR. Two $\mu$ of the prepared extract of each isolate was used as DNA template for PCR amplification. The amplification mixture was prepared in a final volume of $25 \mu \mathrm{L}$. Each PCR mixture contained $12.5 \mu \mathrm{L}$ of PCR master mix $2 \mathrm{x}, 1.5 \mu \mathrm{L}$ of forward primer, 1.5 $\mu \mathrm{L}$ of reverse primer, $2 \mu \mathrm{L}$ of DNA template and nuclease free water to $7.5 \mu \mathrm{L}$. PCR cycling programs were performed using PCR machine and amplification of tested genes was performed in cycles with initial denaturing at $94^{\circ} \mathrm{C}$ for 5 minutes. Then, 35 cycles were performed. In each cycle, denaturation was at $94^{\circ} \mathrm{C}$ for 30 seconds, primer annealing for 30 seconds and elongation at $72{ }^{\circ} \mathrm{C}$ for 90seconds. Following these cycles, a final elongation step was performed at $72^{\circ} \mathrm{C}$ for 10 minutes. Then, the obtained amplification products were separated by electrophoresis $1 \%$ agarose gel at $100 \mathrm{~V}$ for $1 \mathrm{~h}$ and photographed under UV light (UV-TM-25-230V; Hoefer, USA) after staining with Ethidium bromide (Sambrook and Russel, 2001, Martins et al., 2011).

Screening for the potential efflux pump inhibitor by acridine orange agar method

In order to screen for the potential ability of metformin to inhibit efflux, the cartwheel assay was used in the presence of $1 / 4$ MIC of metformin and fluorescence was recorded and compared to control plates without tested drugs.

Minimum inhibitory concentration (MIC) determination
The minimum inhibitory concentrations (MIC) of different antibiotics and tested agents (metformin, verapamil and ascorbic acid) against selected MDR isolates were determined by the broth microdilution method (CLSI, 2016). The antibiotics used were meropenem, amoxicillin, ampicillin-sulbactam, cefepime, amikacin, ciprofloxacin and tetracycline. Overnight cultures of each isolate on MHA were prepared. A suspension was prepared from each strain in sterile saline to have a visible turbidity equivalent to $0.5 \mathrm{McFarland}$ standard. Then, $50 \mu \mathrm{L}$ of 0.5 McFarland was added to $5 \mathrm{~mL}$ broth to make 1:100 dilution. Aliquots of $50 \mu \mathrm{L}$ of suspension were transferred to the wells of 96 -well micro titer plate which contain $50 \mu \mathrm{L}$ of two-fold serial antibiotic dilutions in Müller -Hinton broth. The plates were incubated at $35-37^{\circ} \mathrm{C}$ for $18-24 \mathrm{~h}$ and MIC was considered as the lowest concentration of antimicrobial agent at which there was no visible growth of the microorganism. The experiment was made in triplicates.

Effect of potential efflux pump inhibitors (EPIs) on the resistance of multidrug resistant isolates to different antimicrobial agents

In order to determine the effect of some well-reported efflux pump inhibitors (ascorbic acid and verapamil) as compared with the suggested drug (metformin) on the susceptibility of the MDR isolates, the MICs of tested antibiotics were determined by broth microdilution method in the presence of $1 / 4$ MIC of the tested agents. The antibiotics used were meropenem, amoxicillin, ampicillinsulbactam, cefepime, amikacin, ciprofloxacin and tetracycline (CLSI, 2016). A four-fold decrease in MIC of antibiotics in the presence of the tested agents was considered indicative of reduced efflux activity (Martins et al., 2013). All assays were performed in triplicate.

\section{Statistical analysis}

Statistical analysis was performed by means of the SPSS 21.0 statistical software (IBM Corporation, Armonk, NY, USA). The chi-square test and Fisher's exact two-tailed test were applied to measure any significant relationship. $P$ value < 0.05 was considered as statistically significant. 


\section{RESULTS}

\section{Phenotypic assessment of multi-drug resistant bacteria for efflux pumps}

All the selected MDR isolates (17 isolates) were subjected to qualitative assessment of efflux pumps by the acridine orange agar method. Concentrations of AO which first promotes fluorescence of tested bacterial isolates were recorded $(P<0.001)$ (Table 2 \& Figure 1). Efflux activity was observed in $93.75 \%$ of isolates.

It can be observed from the results that isolate K150 began to fluoresce at a low concentration of $\mathrm{AO}(1 \mathrm{mg} / \mathrm{L})$ indicating the inability to expel the low concentration of the intercalating dye or in other words a negative efflux pump activity, while other isolates began to fluoresce at higher concentration of AO $(5 \mathrm{mg} / \mathrm{L})$ indicating the presence of efflux pumps that could expel $\mathrm{AO}$ or a positive efflux pump activity.

Table 2 Qualitative assessment of efflux pump activity in $K$. pneumoniae isolates by acridine orange agar method

Acridine orange (mg/L) and degree of fluorescence produced

\begin{tabular}{|c|c|c|c|c|c|c|c|}
\hline $\begin{array}{l}\text { Isolate } \\
\text { No. }\end{array}$ & Efflux activity & 0.5 & 1 & 2 & 5 & 10 & 20 \\
\hline K3 & Positive & - & - & - & + & ++ & ++ \\
\hline K6 & Positive & - & - & - & + & ++ & ++ \\
\hline K8 & Positive & - & - & - & + & ++ & ++ \\
\hline K9 & Positive & - & - & - & + & ++ & ++ \\
\hline K10 & Positive & - & - & - & + & ++ & ++ \\
\hline K20 & Positive & - & - & - & + & ++ & ++ \\
\hline K21 & Positive & - & - & - & + & ++ & ++ \\
\hline K22 & Positive & - & - & - & + & ++ & ++ \\
\hline K23 & Positive & - & - & - & + & ++ & ++ \\
\hline K24 & Positive & - & - & - & + & ++ & ++ \\
\hline K39 & Positive & - & - & - & + & ++ & ++ \\
\hline $\mathrm{k} 102$ & Positive & - & - & - & + & ++ & ++ \\
\hline K107 & Positive & - & - & - & + & ++ & ++ \\
\hline K120 & Positive & - & - & - & + & ++ & ++ \\
\hline K139 & Positive & - & - & - & + & ++ & ++ \\
\hline K150 & Negative & - & + & + & ++ & ++ & ++ \\
\hline K151 & Positive & - & - & - & + & ++ & ++ \\
\hline
\end{tabular}

Legend: $\mathrm{K}=K$. pneumoniae, $-=$ no fluorescence, $+=$ fluorescence, $++=$ high fluorescence
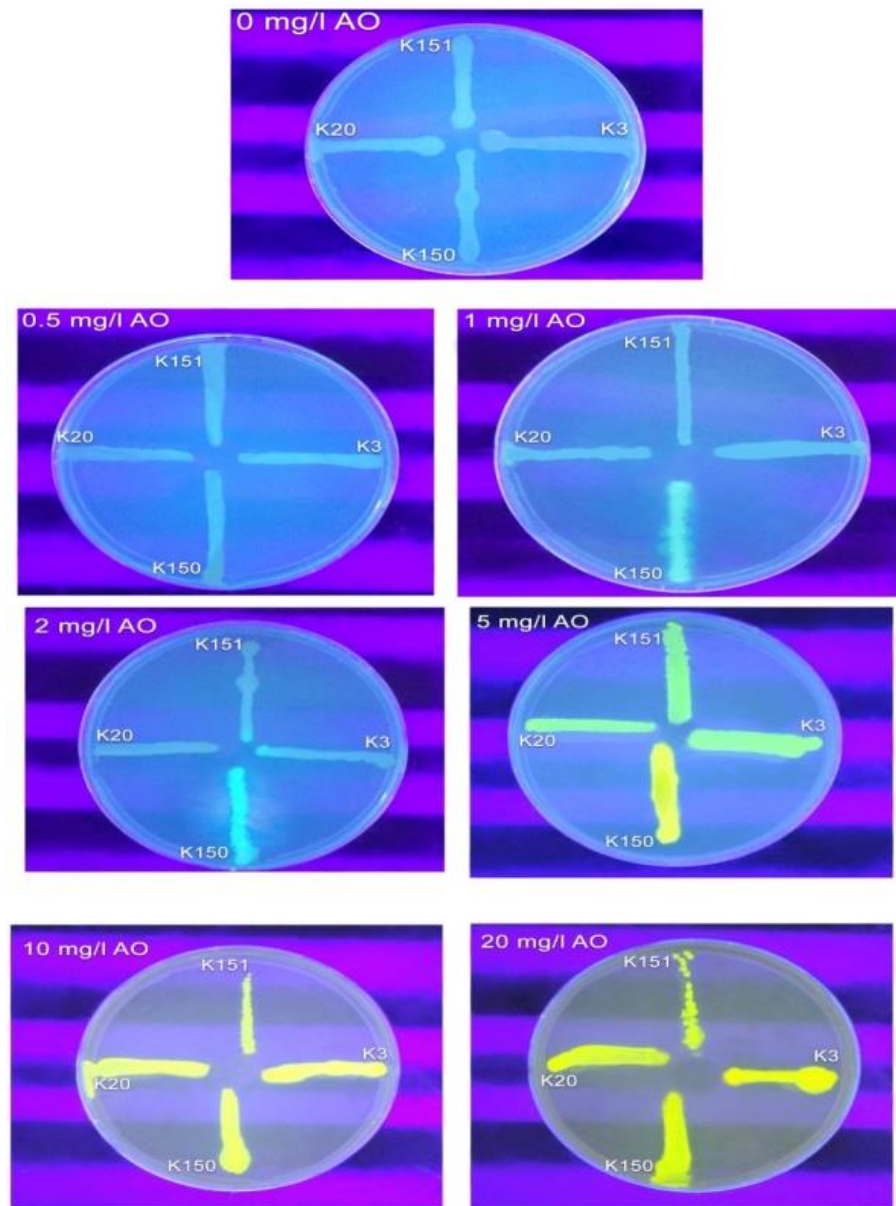

Figure 1 Qualitative assessment of efflux pumps activity by acridine orange aga method. Different $K$. pneumoniae isolates were streaked on agar plates with increasing concentrations of $\mathrm{AO}$ and the ability of the cells to produce fluorescence was detected using UV trans-illuminator. Isolates K3, K20 and K151 showed fluorescence at higher concentrations of AO (5, 10 and $20 \mathrm{mg} / \mathrm{L})$ indicating a positive efflux pump activity, while K150 shows fluorescence at a low concentration of AO indicating negative efflux pump activity.

\section{Genotypic detection of efflux pump genes by PCR}

To confirm the presence of efflux pump as an antibiotic resistance mechanism in MDR isolates, the seventeen MDR isolates were tested for the presence of genes encoding efflux pump (acrAB, tolC, mdtk, ompk35 and ompk36) in K. pneumonia by PCR amplification. As shown in table 3 and figures (2-6), tested genes were found in 15 isolates, one isolate (K8) was lacking ompk36. On the other hand, one isolate (K150) showed only ompk35, while other efflux genes were absent. This may explain the inability of this isolate to expel $\mathrm{AO}$ in the phenotypic assay unlike the other isolates.

Table 3 Genotypic investigation of efflux pump genes among MDR $K$. pneumoniae isolates.

\begin{tabular}{|c|c|c|c|c|c|}
\hline Isolate No. & $\begin{array}{l}\text { acrAB } \\
312 \text { bp }\end{array}$ & $\begin{array}{l}\text { tolC } \\
527 \text { bp }\end{array}$ & $\begin{array}{l}\text { mdtk } \\
453 \text { bp }\end{array}$ & $\begin{array}{l}\text { ompk35 } \\
241 \text { bp }\end{array}$ & $\begin{array}{l}\text { ompk36 } \\
305 \text { bp }\end{array}$ \\
\hline K3 & + & + & + & + & + \\
\hline K6 & + & + & + & + & + \\
\hline K39 & + & + & + & + & + \\
\hline K120 & + & + & + & + & + \\
\hline K107 & + & + & + & + & + \\
\hline K20 & + & + & + & + & + \\
\hline K139 & + & + & + & + & + \\
\hline K10 & + & + & + & + & + \\
\hline K102 & + & + & + & + & + \\
\hline $\mathrm{K} 150$ & - & - & - & + & - \\
\hline K24 & + & + & + & + & + \\
\hline K9 & + & + & + & + & + \\
\hline K8 & + & + & + & + & - \\
\hline K151 & + & + & + & + & + \\
\hline K21 & + & + & + & + & + \\
\hline K22 & + & + & + & + & + \\
\hline K23 & + & + & + & + & + \\
\hline
\end{tabular}

Legend: $\mathrm{K}=$ K. pneumoniae, - = absent,$+=$ present

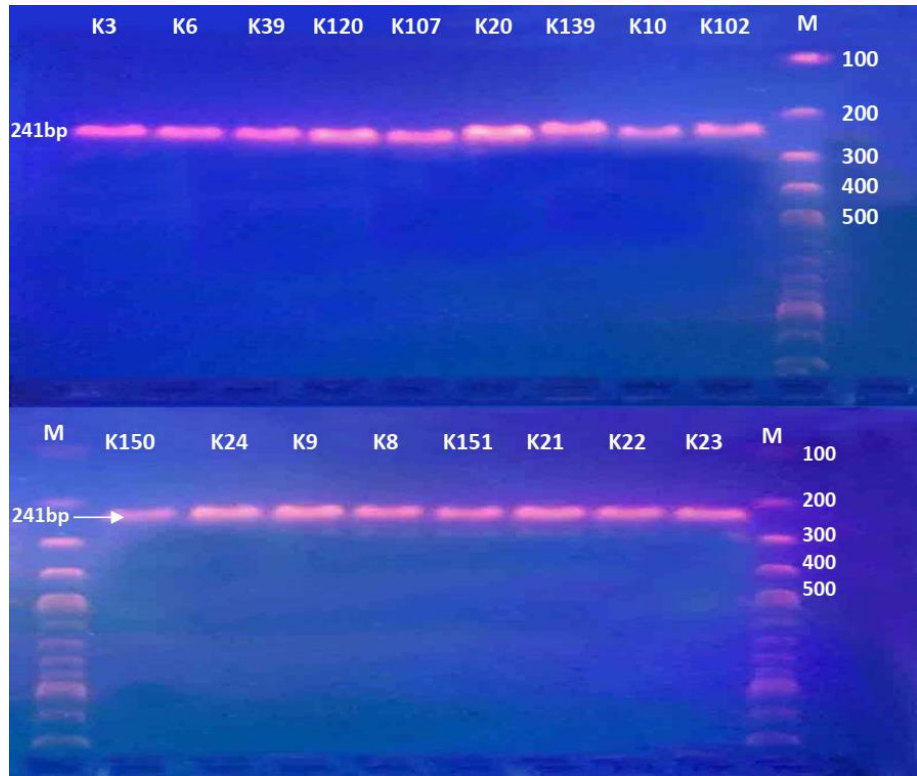

Figure 2 Agarose gel electrophoresis of PCR of ompk35. M; marker (100 bp) Isolates 3, 6, 39, 120, 107, 20, 139, 10, 102,150, 24, 9, 8, 151, 21, 22 and 23 showed a band at approximately $241 \mathrm{bp}$ that corresponds to ompk 35 . 


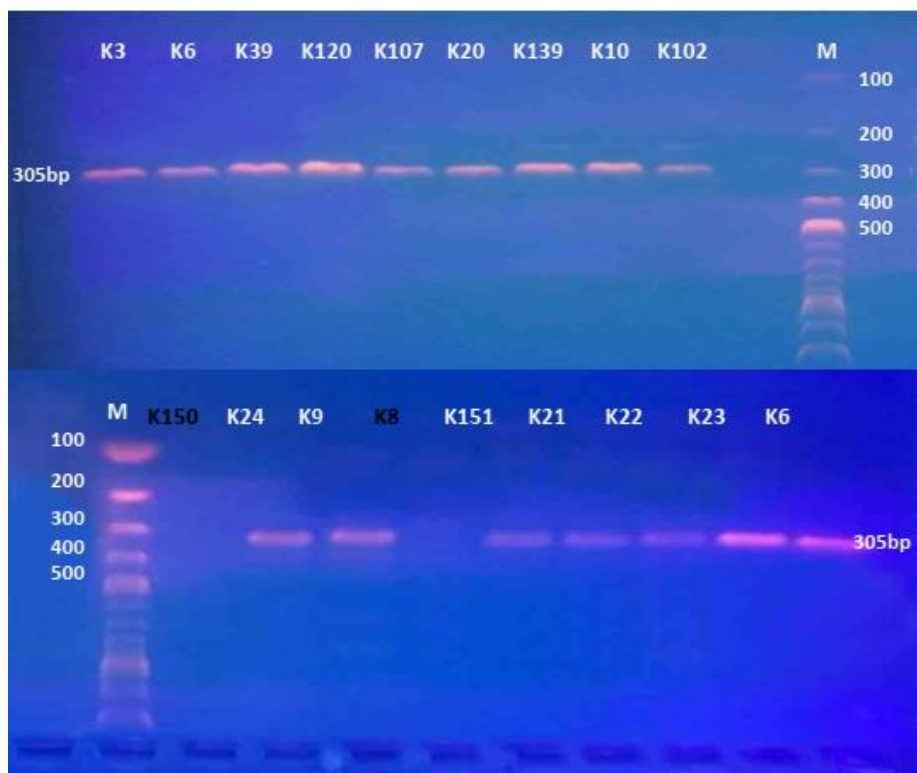

Figure 3 Agarose gel electrophoresis of PCR of ompk36. M; marker (100 bp). Isolates $3,6,39,120,107,20,139,10,102,24,9,151,21,22,23$ and 6 showed a band at approximately $305 \mathrm{bp}$ that corresponds to ompk36.

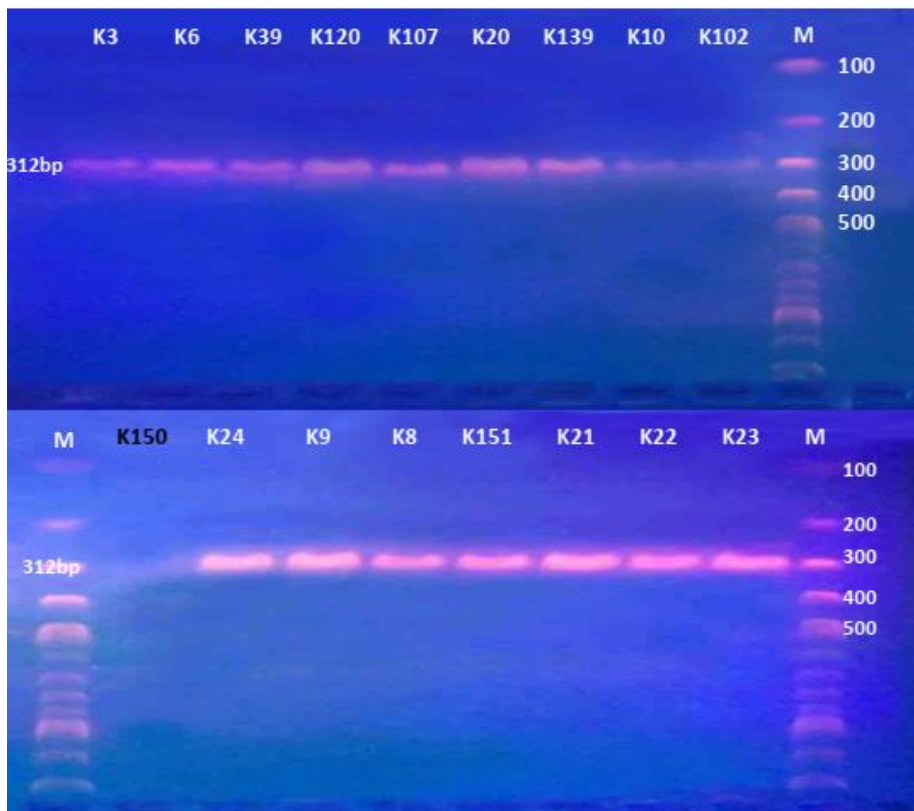

Figure 4 Agarose gel electrophoresis of PCR of $a c r A B$. M; marker (100 bp) Isolates $3,6,39,120,107,20,139,10,102,24,9,8,151,21,22$ and 23 showed a band at approximately 312 bp that corresponds to $a c r A B$.

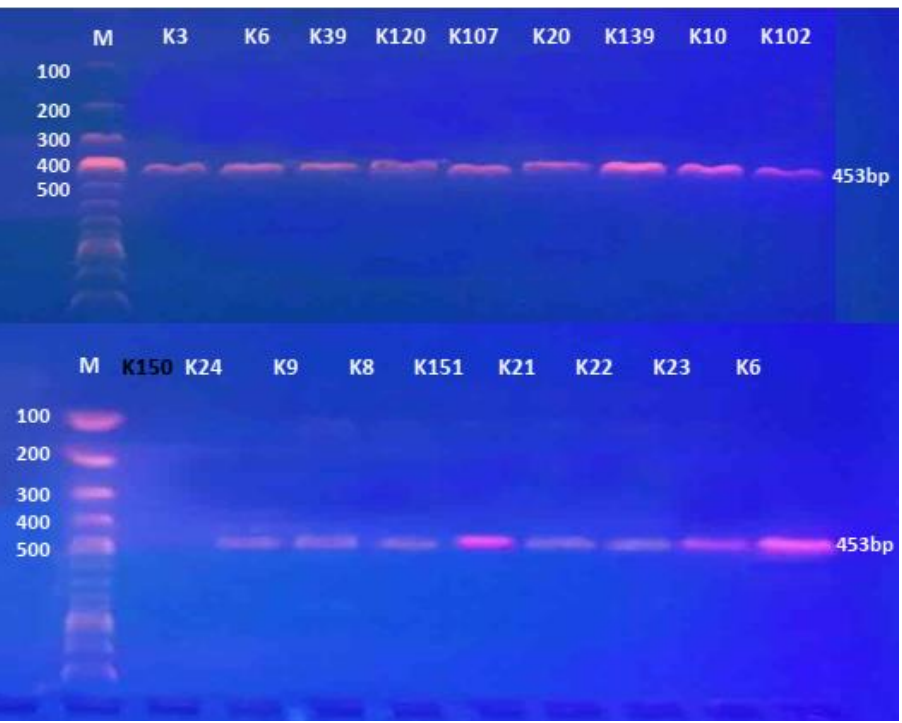

Figure 5 Agarose gel electrophoresis of PCR of $m d t k$. M; marker (100 bp). Isolates $3,6,20,120,107,20,139,10,102,24,9,8,151,21,22,23$ and 6 showed a bana at approximately $453 \mathrm{bp}$ that corresponds to $m d t k$.

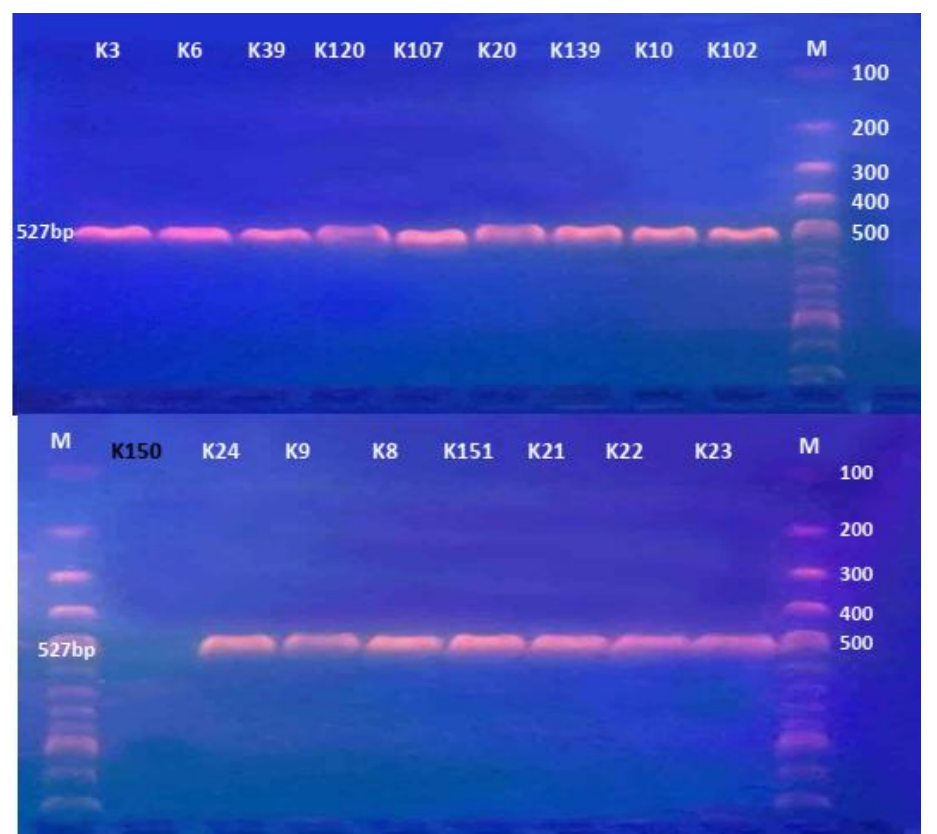

Figure 6 Agarose gel electrophoresis of PCR of tolC. M; marker (100 bp) Isolates $3,6,39,120,107,20,139,10,102,24,9,8,151,21,22$ and 23 showed a band at approximately $527 \mathrm{bp}$ that corresponds to tolC.

\section{Antibiotic susceptibility of MDR bacteria}

In order to test the effect of the tested agents on the susceptibility of MDR $K$. pneumonia isolates to different selected antibiotics, the MICs of these antibiotics against sixteen MDR K. pneumoniae that showed efflux activity by phenotypic and genotypic investigation were determined by the broth microdilution method according to CLSI (2016) as shown in table 4.

Table 4 Susceptibility of MDR isolates to selected antimicrobial agents

\begin{tabular}{lccccccc}
\hline \multirow{2}{*}{$\begin{array}{l}\text { Isolate } \\
\text { number }\end{array}$} & $\begin{array}{c}\text { ME } \\
\text { M }\end{array}$ & AML & SAM & FEP & AK & CIP & \multirow{2}{*}{ TE } \\
\hline K3 & 512 & 512 & $1024 / 512$ & 1024 & 1024 & 16 & 2048 \\
\hline K6 & 32 & 64 & $128 / 64$ & 64 & 128 & 16 & 1024 \\
\hline K8 & 128 & 512 & $1024 / 512$ & 128 & 1024 & 64 & 2048 \\
\hline K9 & 512 & 256 & $512 / 256$ & 1024 & 512 & 128 & 512 \\
\hline K10 & 16 & 512 & $1024 / 512$ & 32 & 1024 & 512 & 128 \\
\hline K20 & 128 & 512 & $2048 / 1024$ & 256 & $>2048$ & 1024 & 256 \\
\hline K21 & 32 & 512 & $128 / 64$ & 16 & 64 & 256 & 512 \\
\hline K22 & 128 & 32 & $1024 / 512$ & 512 & 512 & 2048 & 128 \\
\hline K23 & 32 & 1024 & $1024 / 512$ & 512 & 4096 & 512 & 1024 \\
\hline K24 & 2048 & 512 & $512 / 256$ & 16 & 128 & 256 & 128 \\
\hline K39 & 128 & 32 & $1024 / 512$ & 1024 & 4096 & 128 & 64 \\
\hline K102 & 64 & 32 & $128 / 64$ & 1024 & 4096 & 32 & 32 \\
\hline K107 & 32 & 64 & $1024 / 512$ & 1024 & 4096 & 1024 & 2048 \\
\hline K120 & 2048 & 512 & $512 / 256$ & 16 & 128 & 256 & 128 \\
\hline K139 & 64 & 2048 & $2048 / 1024$ & 512 & 4096 & 16 & 128 \\
\hline K151 & 2048 & 256 & $256 / 128$ & 256 & 2048 & 128 & 16 \\
\hline Legend & 1 & & & & \\
\hline
\end{tabular}

Legend: MEM: meropenem AML: amoxicillin SAM: (ampicillin-sulbactam) FEP: cefepime AK: amikacin CIP: ciprofloxacin TE: tetracycline

\section{Metformin inhibited efflux pump activity in MDR isolates in the AO agar method}

All the sixteen MDR K. pneumonia isolates containing efflux pumps were subjected to qualitative assessment of efflux pumps inhibition by the acridine orange agar method in the presence of $1 / 4 \mathrm{MIC}$ of metformin $(50 \mathrm{mg} / \mathrm{ml})$. Concentrations of AO which first promote fluorescence of tested bacterial isolates were recorded (Table 5 \& Figure 7). Metformin was able to inhibit efflux pump activity in tested MDR $K$. pneumonia isolates. All isolates fail to expel $\mathrm{AO}$ even at low concentration in the presence of metformin as shown by the ability of the isolates to produce fluorescence at all concentrations of $\mathrm{AO}$. 
Table 5 Inhibition of efflux activity in MDR $K$. pneumonia isolates by metformin in the acridine orange agar method

\section{$\mathrm{AO}(\mathrm{mg} / \mathrm{L})$ and degree of fluorescence produced}

\begin{tabular}{l|c|c|c|c|c|c|c}
\hline $\begin{array}{l}\text { Isolate } \\
\text { No. }\end{array}$ & Efflux activity & 0.5 & 1 & 2 & 5 & 10 & 20 \\
\hline K3 & Negative & + & + & + & ++ & ++ & ++ \\
\hline K6 & Negative & + & + & + & ++ & ++ & ++ \\
\hline K8 & Negative & + & + & + & ++ & ++ & ++ \\
\hline K9 & Negative & + & + & + & ++ & ++ & ++ \\
\hline K10 & Negative & + & + & + & ++ & ++ & ++ \\
\hline K20 & Negative & + & + & + & ++ & ++ & ++ \\
\hline K21 & Negative & + & + & + & ++ & ++ & ++ \\
\hline K22 & Negative & + & + & + & ++ & ++ & ++ \\
\hline K23 & Negative & + & + & + & ++ & ++ & ++ \\
\hline K24 & Negative & + & + & + & ++ & ++ & ++ \\
\hline K39 & Negative & + & + & + & ++ & ++ & ++ \\
\hline k102 & Negative & + & + & + & ++ & ++ & ++ \\
\hline K107 & Negative & + & + & + & ++ & ++ & ++ \\
\hline K120 & Negative & + & + & + & ++ & ++ & ++ \\
\hline K139 & Negative & + & + & + & ++ & ++ & ++ \\
\hline K151 & Negative & + & + & + & ++ & ++ & ++ \\
\hline
\end{tabular}

Legend: $\mathrm{K}=K$. pneumoniae, $-=$ no fluorescence, $+=$ fluorescence, $++=$ high fluorescence
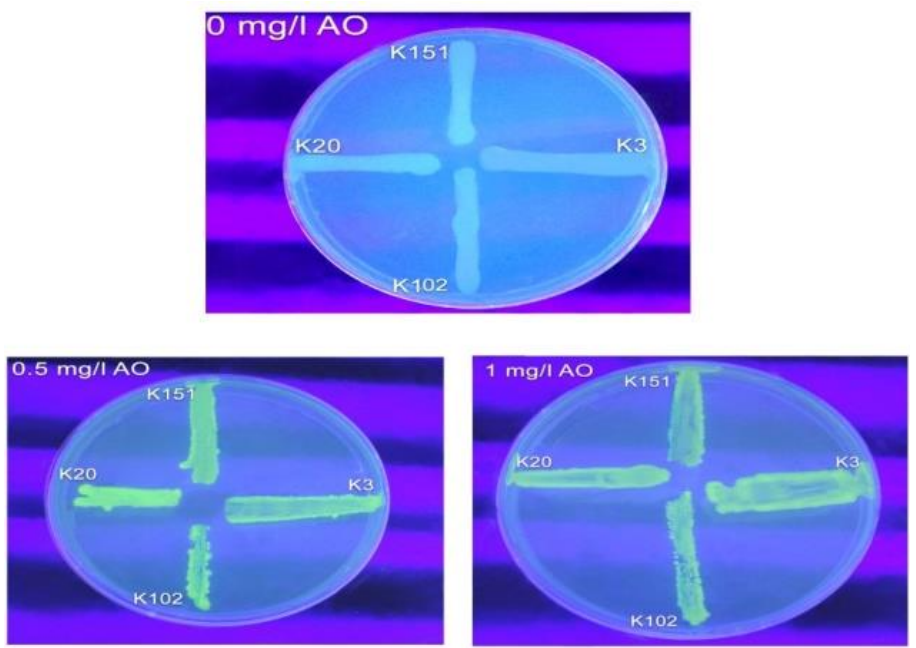
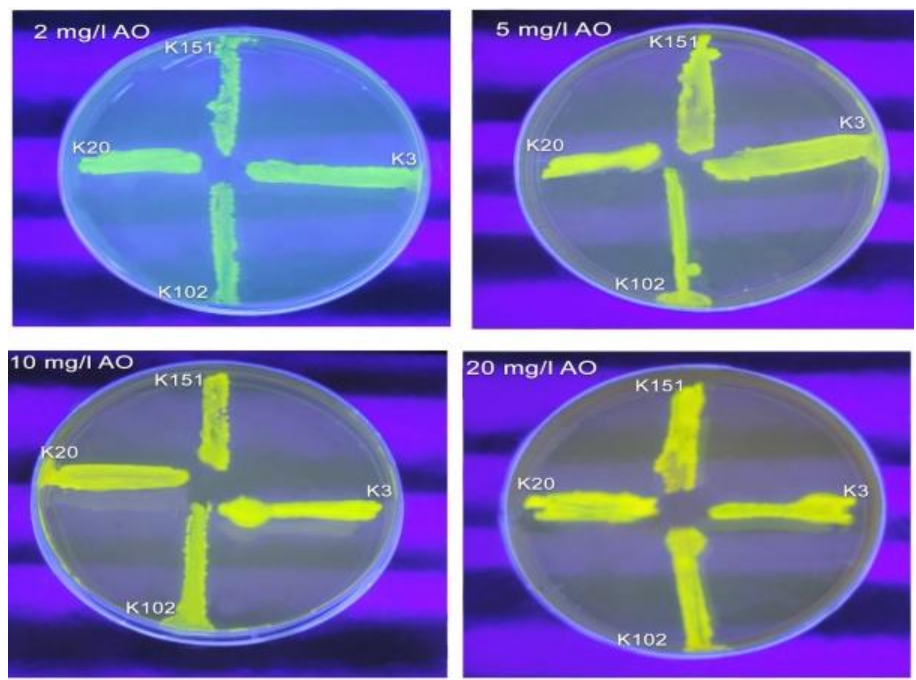

Figure 7 Inhibition of efflux pump activity by sub-inhibitory concentration of metformin. MDR K. pneumonia isolates showed fluorescence at all concentartions of $\mathrm{AO}$ and could not expel the dye in the presence of metformin.

Metformin, verapamil and ascorbic acid could synergize antibiotics against multi-drug resistant isolates. The susceptibility of MDR isolates to selected antibiotics was again determined in the presence of $1 / 4$ MIC of metformin $(50 \mathrm{mg} / \mathrm{mL})$, ascorbic acid $(5 \mathrm{mg} / \mathrm{mL})$ and verapamil $(1.25 \mathrm{mg} / \mathrm{mL})$. As shown in tables (6-8) and figures (8-10), metformin and the well-reported efflux pump inhibitors verapamil and ascorbic acid potentiated activity of all tested antibiotics. Metformin augmented meropenem in all isolates, while ascorbic acid and verapamil potentiated it in $75 \%$ of isolates, respectively. Furthermore, amoxicillin was augmented by both ascorbic acid and verapamil in $93.75 \%$ of isolates and by metformin in $81.25 \%$ of isolates. Each of ascorbic acid and metformin showed synergism with ampicillin-sulbactam in $75 \%$ of isolates, while verapamil showed similar activity in $81.25 \%$ of isolates. The three agents showed similar synergy with cefepime in $93.75 \%$ of isolates. Moreover, ascorbic acid synergized amikacin in all isolates, more than both verapamil and metformin $(93.75 \%)$. Also, all tested $K$. pneumonia isolates showed a higher sensitivity to ciprofloxacin when combined with metformin, while ciprofloxacin was potentiated in $81.25 \%$ and $68.75 \%$ of isolates when combined with ascorbic acid and verapamil, respectively. Tetracycline was augmented by ascorbic acid and verapamil in $93.75 \%$ of isolates, each, while it was potentiated by metformin in $75 \%$ of isolates.

Table 6 Synergistic activity of ascorbic acid with antibiotics against MDR K. pneumonia isolates

\begin{tabular}{lccccccc}
\hline \multirow{2}{*}{ Isolate number } & \multicolumn{7}{c}{ MIC (Fold decrease) } \\
\cline { 2 - 8 } & MEM & AML & SAM & FEP & AK & CIP & TE \\
\hline K3 & $8(64)$ & $32(16)$ & $256 / 128(4)$ & $8(16)$ & $128(8)$ & $8(2)$ & $64(32)$ \\
\hline K6 & $32(\mathrm{ND})$ & $1(64)$ & $16 / 8(8)$ & $4(16)$ & $4(32)$ & $16(\mathrm{ND})$ & $128(8)$ \\
\hline K8 & $64(2)$ & $16(32)$ & $512 / 256(2)$ & $2(64)$ & $32(32)$ & $8(8)$ & $128(16)$ \\
\hline K9 & $8(64)$ & $32(8)$ & $64 / 32(8)$ & $32(32)$ & $16(32)$ & $2(64)$ & $8(64)$ \\
\hline K10 & $0.25(64)$ & $8(64)$ & $256 / 128(4)$ & $1(32)$ & $64(16)$ & $32(16)$ & $16(8)$ \\
\hline K20 & $32(4)$ & $16(32)$ & $256 / 128(8)$ & $32(8)$ & $>128(32)$ & $16(64)$ & $4(64)$ \\
\hline K21 & $16(2)$ & $16(32)$ & $16 / 8(8)$ & $1(16)$ & $16(4)$ & $8(32)$ & $8(64)$ \\
\hline K22 & $2(64)$ & $2(16)$ & $128 / 64(8)$ & $32(16)$ & $16(32)$ & $32(64)$ & $2(64)$ \\
\hline K23 & $2(16)$ & $128(8)$ & $128 / 64(8)$ & $8(64)$ & $512(8)$ & $8(64)$ & $64(16)$ \\
\hline K24 & $64(32)$ & $8(64)$ & $256 / 128(2)$ & $16(\mathrm{ND})$ & $16(8)$ & $8(32)$ & $2(64)$ \\
\hline K39 & $16(8)$ & $2(16)$ & $128 / 64(8)$ & $128(8)$ & $128(32)$ & $128(\mathrm{ND})$ & $1(64)$ \\
\hline K102 & $32(2)$ & $32(\mathrm{ND})$ & $16 / 8(8)$ & $128(8)$ & $1024(4)$ & $2(64)$ & $1(32)$ \\
\hline K107 & $1(32)$ & $4(16)$ & $512 / 256(2)$ & $64(16)$ & $128(32)$ & $64(16)$ & $128(16)$ \\
\hline K120 & $128(16)$ & $8(64)$ & $64 / 32(8)$ & $1(16)$ & $16(8)$ & $8(32)$ & $32(4)$ \\
\hline K139 & $1(64)$ & $256(8)$ & $512 / 256(8)$ & $8(64)$ & $128(32)$ & $1(16)$ & $4(32)$ \\
\hline K151 & $64(32)$ & $8(32)$ & $256 / 128(\mathrm{ND})$ & $4(64)$ & $256(8)$ & $32(4)$ & $16(\mathrm{ND})$ \\
\hline Le
\end{tabular}

Legend: MEM: meropenem AML: amoxicillin SAM: (ampicillin, sulbactam) FEP: cefepime AK: amikacin CIP: ciprofloxacin TE: tetracycline, ND: no decrease in MIC 
Table 7 Synergistic activity of verapamil with antibiotics against MDR K. pneumonia isolates.

\begin{tabular}{|c|c|c|c|c|c|c|c|}
\hline \multirow{2}{*}{ Isolate number } & \multicolumn{7}{|c|}{ MIC (Fold decrease) } \\
\hline & MEM & AML & SAM & FEP & $\mathrm{AK}$ & CIP & TE \\
\hline K3 & $16(32)$ & $8(64)$ & $8 / 4(128)$ & $64(16)$ & $16(64)$ & 16(ND) & $16(64)$ \\
\hline K6 & $8(4)$ & $1(64)$ & $64 / 32(2)$ & $4(16)$ & $2(64)$ & $8(2)$ & $32(16)$ \\
\hline K8 & $64(2)$ & $8(64)$ & $8 / 4(128)$ & $128(\mathrm{ND})$ & $64(32)$ & $4(16)$ & $64(16)$ \\
\hline K9 & $16(32)$ & $32(8)$ & $128 / 64(4)$ & $128(8)$ & $4(128)$ & $2(64)$ & $4(128)$ \\
\hline K10 & $8(2)$ & $4(128)$ & $8 / 4(128)$ & $2(16)$ & $16(64)$ & $32(16)$ & $32(4)$ \\
\hline K20 & $2(64)$ & $8(64)$ & $128 / 64(16)$ & $4(64)$ & $256(>8)$ & $16(64)$ & $8(32)$ \\
\hline K21 & $2(16)$ & $8(64)$ & $64 / 32(2)$ & $1(16)$ & $2(32)$ & $16(16)$ & $8(64)$ \\
\hline K22 & $32(4)$ & $1(32)$ & $256 / 128(4)$ & $64(8)$ & $16(32)$ & $128(16)$ & $1(128)$ \\
\hline K23 & $1(32)$ & $64(16)$ & $64 / 32(16)$ & $4(256)$ & $128(32)$ & $256(2)$ & $128(8)$ \\
\hline K24 & $32(64)$ & $16(32)$ & $32 / 16(16)$ & $1(16)$ & $2(64)$ & $2(128)$ & $8(16)$ \\
\hline K39 & $64(2)$ & $0.5(64)$ & $2 / 1(512)$ & $2(512)$ & $256(16)$ & 128(ND) & $1(64)$ \\
\hline K102 & $64(\mathrm{ND})$ & $16(2)$ & $2 / 1(64)$ & $16(64)$ & $256(16)$ & $8(4)$ & $8(4)$ \\
\hline K107 & $1(32)$ & $4(16)$ & $256 / 128(4)$ & $128(8)$ & $64(64)$ & $128(8)$ & $256(8)$ \\
\hline K120 & $128(16)$ & $8(64)$ & $32 / 16(16)$ & $2(8)$ & $2(64)$ & $2(128)$ & $2(64)$ \\
\hline K139 & $32(2)$ & $128(16)$ & $16 / 8(128)$ & $4(128)$ & $128(32)$ & $8(2)$ & $2(64)$ \\
\hline K151 & $256(8)$ & $1(256)$ & 256/128(ND) & $32(8)$ & 2048(ND) & $2(64)$ & $8(2)$ \\
\hline
\end{tabular}

Legend: $\mathrm{K}=$ K. pneumoniae, $-=$ no fluorescence, $+=$ fluorescence, $++=$ high fluorescence MEM: meropenem AML: amoxicillin SAM: (ampicillin, sulbactam) FEP: cefepime AK: amikacin CIP: ciprofloxacin TE: tetracycline, ND: no decrease in MIC

Table 8 Synergistic activity of metformin with antibiotics against MDR K. pneumonia isolates.

\begin{tabular}{|c|c|c|c|c|c|c|c|}
\hline \multirow{2}{*}{ Isolate number } & \multicolumn{7}{|c|}{ MIC (Fold decrease) } \\
\hline & MEM & AML & SAM & FEP & $\mathrm{AK}$ & CIP & TE \\
\hline K3 & $16(32)$ & $16(32)$ & $256 / 128(4)$ & $256(4)$ & $32(32)$ & $2(8)$ & $64(32)$ \\
\hline K6 & $1(32)$ & $1(64)$ & 128/64(ND) & $2(32)$ & $4(32)$ & $1(16)$ & $128(8)$ \\
\hline K8 & $32(4)$ & $128(4)$ & $512 / 256(2)$ & $32(4)$ & $16(64)$ & $1(64)$ & $128(16)$ \\
\hline K9 & $32(16)$ & $4(64)$ & $32 / 16(16)$ & $32(32)$ & $32(16)$ & $32(4)$ & $32(16)$ \\
\hline K10 & $2(8)$ & $32(16)$ & $8 / 4(128)$ & $8(4)$ & $32(32)$ & $32(16)$ & $64(2)$ \\
\hline K20 & $4(32)$ & $32(16)$ & $4 / 2(512)$ & $4(64)$ & $64(>32)$ & $8(128)$ & $32(8)$ \\
\hline K21 & $2(16)$ & $8(64)$ & $64 / 32(2)$ & $2(8)$ & $1(64)$ & $4(64)$ & $256(2)$ \\
\hline K22 & $4(32)$ & $32(\mathrm{ND})$ & $16 / 8(64)$ & $16(32)$ & $8(64)$ & $16(128)$ & $32(4)$ \\
\hline K23 & $0.5(64)$ & $512(2)$ & $8 / 4(128)$ & $32(16)$ & $32(128)$ & $32(16)$ & $2(512)$ \\
\hline K24 & $8(256)$ & 512(ND) & $16 / 8(32)$ & 16(ND) & $4(32)$ & $64(8)$ & $8(16)$ \\
\hline K39 & $4(32)$ & $2(16)$ & $4 / 2(256)$ & $64(16)$ & $16(256)$ & $2(64)$ & $32(2)$ \\
\hline K102 & $8(8)$ & $2(16)$ & $32 / 16(4)$ & $128(8)$ & 1024(4) & $1(32)$ & $4(8)$ \\
\hline K107 & $2(16)$ & $1(64)$ & $16 / 8(128)$ & $32(32)$ & $512(8)$ & $128(8)$ & $256(8)$ \\
\hline K120 & $256(8)$ & $32(16)$ & $16 / 8(32)$ & $1(16)$ & $8(16)$ & $4(64)$ & $64(2)$ \\
\hline K139 & $0.25(256)$ & $256(8)$ & $32 / 16(64)$ & $32(16)$ & $64(64)$ & $2(8)$ & $4(32)$ \\
\hline K151 & $8(128)$ & $2(128)$ & $256 / 128(\mathrm{ND})$ & $16(16)$ & $2048(\mathrm{ND})$ & $2(64)$ & $1(16)$ \\
\hline
\end{tabular}

Legend: $\mathrm{K}=$ K. pneumoniae, $-=$ no fluorescence, $+=$ fluorescence, $++=$ high fluorescence MEM: meropenem AML: amoxicillin SAM: (ampicillin, sulbactam) FEP: cefepime AK: amikacin CIP: ciprofloxacin TE: tetracycline, ND: no decrease in MIC

\section{DISCUSSION}

K. pneumoniae accounts for a significant proportion of healthcare-associated infections. Healthcare-associated infections are very common in patients suffering from respiratory tract infections. In addition to nosocomial pneumonia, $K$. pneumoniae is a leading cause of other healthcare-associated infections such as urinary and blood stream infections, all are recognized as an urgent threat to public health (Bluestone et al., 2002). Immunocompromised individuals are more seriously affected by $K$. pneumonia infections, but the emergence and spread of hypervirulent strains have increased the number of susceptible to include also healthy people (He et $\boldsymbol{a l}$., 2015). The high rate of emergence of MDR $K$. pneumoniae strains have rendered the treatment of infection very difficult (Jabar and Hassoon, 2019). Efflux pumps are involved in multidrug resistance in clinical $K$. pneumoniae isolates (Wu et al. 2009). Efflux of antibiotics outside bacterial cells reduces their intracellular concentration and therefore increases the likelihood of bacterial survival (Piddock, 2006).

In this study, the AO agar method was used for the phenotypic assessment of efflux pumps in MDR clinical $K$. pneumoniae isolates and drug efflux pump activity was identified in $93.7 \%$ of $K$. pneumoniae isolates. The most important antibiotic resistance genes of $K$. pneumoniae, acrAB, tolC, mdtk, ompk35, and ompk36 were predominant amongst $K$. pneumoniae isolated from hospitalacquired RTI (Liao et al., 2009). The increased efflux of the antimicrobial agents results in the decrease of its intracellular concentration, giving bacteria the opportunity to survive. The presence of the efflux pump system (AcrAB-tolC) was significantly related to antibiotic resistance and the AcrAB efflux pump was more predominant than mdtk in K. pneumonia (Chen et al., 2010, Padilla et al., 2010, Kim et al., 2011). However, in current study, the prevalence of $a c r A$, acr $B$ and tolC that encode the AcrAB-tolC efflux pump components was similar to that of $m d t k$ gene.

The outer membrane of Gram negative bacteria displays poor permeability to both hydrophobic and hydrophilic compounds. As a result, most antibiotics, apart from $\beta$-lactams need porins to cross the membrane to get access to reach their intracellular targets (Nikaido, 2003). It was previously reported that carbapenems and ciprofloxacin resistance increased by the loss of porins
OmpK35 and OmpK36 (Kaczmarek et al., 2006). Astonishingly, OmpK35 and OmpK36 porins were present in all but one isolate and was not correlated to MDR. A similar surprising result was reported by Wasfi et al. (2016) that was explained by the presence of point or promoter region mutations or disruption in the protein coding sequence (Doumith et al., 2009). On the other hand, Ompk35 and Ompk36 also play a role in K. pneumoniae virulence and infection (Piddock 2006, Chen et al., 2010, Padilla et al., 2010)

Due to the significant role of efflux pump in MDR, it is vital to screen for agents that can interfere with efflux activity to reverse the resistance to antibiotics. Metformin inhibited mammalian P-glycoprotein (P-gp) efflux activity in situ and down-regulated P-gp expression in vitro (Abbasi et al., 2016). In the current study, the reference efflux pump inhibitors ascorbic acid and verapamil, and the potential one metformin significantly reduced the MICs of antibiotics meropenem, amoxicillin, ampicillin-sulbactam, cefepime, amikacin, ciprofloxacin and tetracycline. The synergistic activity of ascorbic acid was previously reported with chloramphenicol, meropenem, cefepime and cefoperazone against $P$. aeruginosa (Abbas, 2012).

In order to compare the synergistic activities of metformin with those of ascorbic acid and verapamil, the fold decrease in MIC found with $50 \%$ of K. pneumoniae isolates in which synergy was found was calculated. Based on this calculation, it was found that verapamil was the most potent efflux inhibitor, followed by metformin, and both showed higher activities than ascorbic acid. Ascorbic acid showed synergism with tetracycline, amoxicillin and meropenem ( $\leq 32$ folds) followed by cefepime and amikacin ( $\leq 16$ folds), while the least synergism was obtained with ampicillin-sulbactam and ciprofloxacin ( $\leq 8$ folds). For verapamil, the potentiation was found with amikacin and amoxicillin $(\leq 64$ folds) followed by meropenem and tetracycline ( $\leq 32$ folds), ampicillin-sulbactam, cefepime and ciprofloxacin ( $\leq 16$ folds). Moreover, when combined with metformin, the most synergized antibiotic was ampicillin-sulbactam ( $\leq 64$ folds), followed by meropenem, and amikacin ( $\leq 32$ folds), amoxicillin, cefepime, tetracycline and ciprofloxacin ( $\leq 16$ folds). In our previous study, metformin was found to be a potent inhibitor of efflux pumps in Staphylococcus aureus. Metformin was more potent than the standard efflux pump inhibitor verapamil. Metformin synergized the antibiotics linezolid, levofloxacin, doxycycline, ampicillin-sulbactam, 
vancomycin, co-trimoxazole, amikacin and imipenem. The reduction in MICs was high to the extent of 1024-2048 folds (Baiomy et al., 2020). Furthermore, metformin augmented doxycycline and minocycline, against MDR S. aureus, S. enteritidis, E. faecalis and E. coli. Moreover, metformin could serve as a quorum sensing and virulence inhibitor in Pseudomonas aeruginosa (Abbas et al., 2017, Hegazy et al., 2020).

\section{CONCLUSION}

Efflux pumps play a significant role in resistance of clinical $K$. pneumoniae isolates to antibiotics. AcrAB and Mdtk efflux pumps are common in pneumoniae. Efflux pump inhibitors can synergize antibiotics. Metformin is a new efflux pump inhibitor that can resensitize $K$. pneumoniae to antibiotics.

\section{Conflict of interest: There is no conflict of interest}

Funding: There is no funding source for this research

\section{REFERENCES}

Abbas, H. A. (2012) Modulation of antibiotic activity against Pseudomonas aeruginosa by $\mathrm{N}$-acetylcysteine, ambroxol and ascorbic acid. Asian Journal of Research in Pharmaceutical Sciences, 2,123-128.

Abbas, H. A., Elsherbini, A. M., \& Shaldam, M. A. (2017). Repurposing metformin as a quorum sensing inhibitor in Pseudomonas aeruginosa. African health sciences, 17(3), 808-819. https://doi.org/10.4314/ahs.v17i3.24

Abbasi, M. M., Valizadeh, H., Hamishehkar, H.\& Zakeri-Milani, P. (2016) Inhibition of P-glycoprotein expression and function by anti-diabetic drugs gliclazide, metformin, and pioglitazone in vitro and in situ. Research in Pharmaceutical Sciences, 11(3),177-86. PMID: 27499787

Auda, I. G., Salman, I. M.A.,\& Odah, J. G. (2020) Efflux pumps of Gramnegative bacteria in brief. Gene Reports. 20: 100666 https://doi.org/10.1016/j.genrep.2020.100666

Baiomy, A. A., Shaker, G. H.\& Abbas, H. A. (2020). Sensitizing multi drug resistant Staphylococcus aureus isolated from surgical site infections to antimicrobials by efflux pump inhibitors. African Health Sciences, 20(4),163245. https://dx.doi.org/10.4314/ahs.v20i4.16

Bluestone, C. D., Gates, G. A., Klein, J. O., Lim, D. J., Mogi, G., Ogra, P. L., Paparella, M. M., Paradise, J. L.\& Tos, M. (2002) 1. Definitions, terminology, and classification of otitis media. Annals of Otology, Rhinology \& Laryngology, 111, 8-18. https://doi.org/10.1177\%2F00034894021110S304 Chen, J. H., Siu, L. K., Fung, C. P., Lin, J. C., Yeh, K. M., Chen, T. L., Tsai, Y. K.\& Chang, F. Y. (2010) Contribution of outer membrane protein K36 to antimicrobial resistance and virulence in Klebsiella pneumoniae. Journal of Antimicrobial Chemotherapy, 65, 986-990. https://doi.org/10.1093/jac/dkq056 Chikere, C. B., Omoni, V. T.\& Chikere, B. O. (2008) Distribution of potential nosocomial pathogens in a hospital environment. African Journal of Biotechnology, 7 (20), 3535-3539.

CLSI-Clinical and Laboratory Standards Institute (2016). Methods for dilution antimicrobial susceptibility tests for bacteria that grow aerobically: Approvated standard, CLSI Document M07-A9. Wayne, USA.

Doumith, M., Ellington, M. J., Livermore, D. M.\& Woodford, N. (2009) Molecular mechanisms disrupting porin expression in ertapenem-resistant Klebsiella and Enterobacter spp. clinical isolates from the UK. Journal of Antimicrobial Chemotherapy, 63, 659-667. https://doi.org/10.1093/jac/dkp029

Du, D., Voss, J. E., Klimont, E., Ohene-Agyei, T., Venter, H., Chiu, W.\& Luisi, B. F. (2014) Structure of the AcrAB-TolC multidrug efflux pump. Nature, 509, 512-515, https://doi.org/10.1038/nature13205.

Serry F. M., EL-Masry E. M., Shaker, G. H.\& Abdelmonem, H. (2008) The role of haemolysin transport system in antimicrobial resistance of haemolytic strains of Escherichia coli and the effect of potential efflux inhibitors. Journal of Pure and Applied Microbiology, 2, 307-318.

Filgona, J., Banerjee, T.\& Anupurba, S. (2015). Role of efflux pumps inhibitor in decreasing antibiotic resistance of Klebsiella pneumoniae in a tertiary hospital in North India. Journal of Infectection in Develpoing Countries, 9, 815-820. https://doi.org/10.3855/jidc.6216

Fournier, P. E., Vallenet, D., Barbe, V., Audic, S., Ogata, H., Poirel, L., Richet, H., Robert, C., Mangenot, S., Abergel, C., Nordmann, P., Weissenbach, J., Raoult, D.\& Claverie, J. M. (2006). Comparative genomics of multidrug resistance in Acinetobacter baumannii. PLoS Genetics, 2,1-7. https://doi.org/10.1371/journal.pgen.0020007

Gupta, D., Singh, A.\& Khan, A. U. (2017) Nanoparticles as efflux pump and biofilm inhibitor to rejuvenate bactericidal effect of conventional antibiotics. Nanoscale Research Letters, 12,454. https://doi.org/10.1186/s11671-017-2222-6 He, F., Fu, Y., Chen, Q., Ruan, Z., Hua, X., Zhou, H.\& Yu, Y. (2015) Tigecycline susceptibility and the role of efflux pumps in tigecycline resistance in KPC-producing Klebsiella pneumoniae. PLoS One, 10, e0119064. https://doi.org/10.1371/journal.pone.0119064

Hegazy, W., Khayat, M. T., Ibrahim, T. S., Nassar, M. S., Bakhrebah, M. A., Abdulaal, W. H., Alhakamy, N. A., \& Bendary, M. M. (2020). Repurposing Anti- diabetic Drugs to Cripple Quorum Sensing in Pseudomonas aeruginosa. Microorganisms, 8(9),

https://doi.org/10.3390/microorganisms 8091285

Iyer, R., Moussa, S. H., Tommasi, R.\& Miller, A. A. (2019) Role of the Klebsiella pneumoniae TolC porin in antibiotic efflux. Research in Microbiology, 170, 112-116. https://doi.org/10.1016/j.resmic.2018.11.003

Jabar, R. M.\& Hassoon, A. H. (2019) The expression of efflux pump AcrAB in MDR Klebsiella pneumoniae isolated from Iraqi patients. Journal of Pharmaceutical Sciences and Research, 11, 423-428.

Kabra, R., Chauhan, N., Kumar, A., Ingale, P.\& Singh, S. (2019). Efflux pumps and antimicrobial resistance: Paradoxical components in systems genomics. Progress in Biophysics and Molecular Biology, 141,15-24. https://doi.org/10.1016/j.pbiomolbio.2018.07.008

Kaczmarek, F. M., Dib-Hajj, F., Shang, W.\& Gootz, T. D. (2006) High-level carbapenem resistance in a Klebsiella pneumoniae clinical isolate is due to the combination of bla(act-1) $\beta$-lactamase production, porin OmpK35/36 insertional inactivation, and down-regulation of the phosphate transport porin PhoE Antimicrobial Agents and Chemotherapy, 50, 3396-3406. https://doi.org/10.1128/AAC.00285-06

Kim, H. G., Hien, T. T., Han, E. H., Hwang, Y. P., Choi, J. H., Kang, K. W. Kwon, K. I., Kim, B. H., Kim, S. K., Song, G. Y., Jeong, T. C.\& Jeong, H. G. (2011) Metformin inhibits P-glycoprotein expression via the NF- $\kappa$ B pathway and CRE transcriptional activity through AMPK activation. British Journal of Pharmacology, 162,1096-1108. $\quad$ https://doi.org/10.1111/j.14765381.2010.01101.x

Kombade, S. P.\& Agrawal, G. N. (2014) Microbiological study of lower respiratory tract infections in ICU patients. International Journal of Current Microbiology and Applied Sciences, 3,749-54.

Li, X. Z.\& Nikaido, H. (2009). Efflux-mediated drug resistance in bacteria Drugs, 69,1555-1623. https://doi.org/10.2165/00003495-200464020-00004

Li, X.Z., Plésiat, P.\& Nikaido, H. (2015). The challenge of efflux-mediated antibiotic resistance in Gram-negative bacteria. Clinical Microbiology Reviews, 28, 337-418. https://doi.org/10.1128/CMR.00117-14

Liao, C. H., Lai, C. C., Hsu, M. S., Huang, Y. T., Chu, F. Y., Hsu, H. S.\& Hsueh, P. R. (2009). Correlation between time to positivity of blood cultures with clinical presentation and outcomes in patients with Klebsiella pneumoniae bacteraemia: prospective cohort study. Clinical Microbiology and Infection, 15,1119-1125. https://doi.org/10.1111/j.1469-0691.2009.02720.x

Liu, Y., Jia, Y., Yang, K., Li, R., Xiao, X., Zhu, K.\& Wang, Z. (2020). Metformin restores tetracyclines susceptibility against multidrug resistant

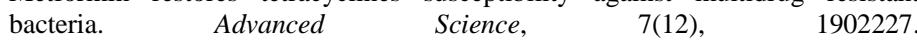
https://doi.org/10.1002/advs.201902227

Louw, G. E., Warren, R. M., Gey Van Pittius, N. C., Leon, R., Jimenez, A. Hernandez-Pando, R., McEvoy, C. R., Grobbelaar, M., Murray, M., van Helden, P. D.\&, Victor, T. C. (2011). Rifampicin reduces susceptibility to ofloxacin in rifampicin-resistant Mycobacterium tuberculosis through efflux. American Journal of Respiratory and Critical Care Medicine, 184,269-276. https://doi.org/10.1164/rccm.201011-1924OC

Martins, M., Mccusker, M. P., Viveiros, M., Couto, I., Fanning, S., Pagès, J. M.\& Amaral, L. (2013). A simple method for assessment of MDR bacteria for over-expressed efflux pumps. Open Microbiol Journal, 7,72-82. https://doi.org/10.2174/1874285801307010072

Martins, M., Viveiros, M., Couto, I., Costa, S. S., Pacheco, T., Fanning, S., Pagès, J. M.\& Amaral, L. (2011). Identification of efflux pump-mediated multidrug-resistant bacteria by the ethidium bromide-agar cartwheel method. In Vivo, 25, 171-178. PMID: 21471531

Nair, M. K.\& Venkitanarayanan, K. S. (2006). Cloning and sequencing of the ompA gene of Enterobacter sakazakii and development of an ompA-targeted PCR for rapid detection of Enterobacter sakazakii in infant formula. Applied and Environmental Microbiology, 72,2539-2546. https://doi.org/10.1128/AEM.72.4.2539-2546.2006

Neyfakh, A. A., Bidnenko, V. E.\& Chen, L. B. (1991). Efflux-mediated multidrug resistance in Bacillus subtilis: similarities and dissimilarities with the mammalian system. Proceedings of the National Academy of Sciences of the United States of America, 88,4781-4785. https://doi.org/10.1073/pnas.88.11.4781 Nikaido, H. (2003). Molecular basis of bacterial outer membrane permeability revisited. Microbiology and Molecular Biology Reviews, 67, 593656. https://doi.org/10.1128/mmbr.67.4.593-656.2003

Okusu, H., Ma, D.\& Nikaido, H. (1996). AcrAB efflux pump plays a major role in the antibiotic resistance phenotype of Escherichia coli multiple-antibioticresistance (Mar) mutants. Journal of Bacteriology, 178, 306-308. https://doi.org/10.1128/jb.178.1.306-308.1996

Padilla, E., Llobet, E., Doménech-Sánchez, A., Martínez-Martínez, L., Bengoechea, J. A.\& Albertí, S. (2010). Klebsiella pneumoniae AcrAB efflux pump contributes to antimicrobial resistance and virulence. Antimicrobial Agents and Chemotherapy, 54,177-183. https://doi.org/10.1128/AAC.00715-09

Piddock, L. J. (2006). Clinically relevant chromosomally encoded multidrug resistance efflux pumps in bacteria. Clinical Microbiology Reviews, 19,382-402. https://doi.org/10.1128/CMR.19.2.382-402.2006 
Prajapati, B., Talsania, N.\& Sonaliya, K. N. (2011). A study on prevalence of acute respiratory tract infections (ARI) in under five children in urban and rural communities of Ahmedabad district, Gujarat. National Journal of Community Medicine, 2,255-259.

Ranjbar, R., Kelishadrokhi, A. F.\& Chehelgerdi, M. (2019). Molecular characterization, serotypes and phenotypic and genotypic evaluation of antibiotic resistance of the Klebsiella pneumoniae strains isolated from different types of hospital-acquired infections. Infection and Drug Resistance, 12, 603. https://doi.org/10.2147/IDR.S199639

Saini, A., Sharma, S.\& Chhibber, S. (2009). Induction of resistance to respiratory tract infection with Klebsiella pneumoniae in mice fed on a diet supplemented with tulsi (Ocimum sanctum) and clove (Syzgium aromaticum) oils. Journal of Microbiology, Immunology and Infection, 42,107-113. PMID: 19597641.

Sambrook, J.\& Russel, D. (2001). Molecular Cloning: A Laboratory Manual. NY: Cold Spring Harbor Laboratory Press, Cold Spring Harbor.

Shi, W., Li, K., Ji, Y., Jiang, Q., Wang, Y., Shi, M.\& Mi, Z. (2013). Carbapenem and cefoxitin resistance of Klebsiella pneumoniae strains associated with porin OmpK36 loss and DHA-1 $\beta$-lactamase production. Brazilian Journal of Microbiology, 44,435-442. https://doi.org/10.1590/S1517-83822013000200015

Singh, S., Kalia, N. P., Joshi, P., Kumar, A., Sharma, P. R., Kumar, A., Bharate, S. B.\& Khan, I. A. (2017). Boeravinone B, A novel dual inhibitor of NorA bacterial efflux pump of Staphylococcus aureus and human P-glycoprotein, reduces the biofilm formation and intracellular invasion of bacteria. Frontiers in Microbiology, 8,1868. https://doi.org/10.3389/fmicb.2017.01868

Sun, J., Deng, Z.\& Yan, A. (2014). Bacterial multidrug efflux pumps: mechanisms, physiology and pharmacological exploitations. Biochemical and Biophysical Research Communication, 465(1),165. https://doi.org/10.1016/j.bbrc.2014.05.090

Surgers, L., Boyd, A., Girard, P. M., Arlet, G.\& Decré, D. (2019). Biofilm formation by ESBL-producing strains of Escherichia coli and Klebsiella pneumoniae. International Journal of Medical Microbiology, 309,13-18. https://doi.org/10.1016/j.ijmm.2018.10.008

Upadhyay, A. K.\& Parajuli, P. (2013). Extended Spectrum B-Lactamase Producing Multidrug-Resistant Klebsiella Species Isolated At National Medical College And Teaching Hospital, Nepal. Asian Journal of Pharmaceutical and Clinical Research, 6(4), 161-164.

Vazquez-Martin, A., Oliveras-Ferraros, C., Del Barco, S., Martin-Castillo, B. Menendez, J. A. (2009). The antidiabetic drug metformin: a pharmaceutical AMPK activator to overcome breast cancer resistance to HER2 inhibitors while decreasing risk of cardiomyopathy. Annals of Oncology, 20,592-595. https://doi.org/10.1093/annonc/mdn758

Wasfi, R., Elkhatib, W. F., Ashour, H. M. (2016). Molecular typing and virulence analysis of multidrug resistant Klebsiella pneumoniae clinical isolates recovered from Egyptian hospitals. Scientific Reports, 6, 38929 https://doi.org/10.1038/srep38929

Wu, K. M., Li, L. H., Yan, J. J., Tsao, N., Liao, T. L., Tsai, H. C., Fung, C. P., Chen, H. J., Liu, Y. M., Wang, J. T., Fang, C. T., Chang, S. C., Shu, H. Y., Liu, T. T., Chen, Y. T., Shiau, Y. R., Lauderdale, T. L., Su, I. J., Kirby, R.\& Tsai, S. F. (2009). Genome sequencing and comparative analysis of Klebsiella pneumoniae NTUH-K2044, a strain causing liver abscess and meningitis. Journal of Bacteriology, 191, 4492-4501. https://doi.org/10.1128/JB.00315-09 Zakikhani, M., Dowling, R., Fantus, I. G., Sonenberg, N., Pollak, M. (2006). Metformin is an AMP kinase-dependent growth inhibitor for breast cancer cells. Cancer Research, 66,10269-10273. https://doi.org/10.1158/0008-5472.CAN-06$\underline{1500}$ 